\title{
Comparison of Stemness and Gene Expression between Gingiva and Dental Follicles in Children
}

\author{
Chung-Min Kang, ${ }^{1}$ Seong-Oh Kim, ${ }^{1}$ Mijeong Jeon, ${ }^{2}$ Hyung-Jun Choi, \\ Han-Sung Jung, ${ }^{3}$ and Jae-Ho Lee ${ }^{1}$ \\ ${ }^{1}$ Department of Pediatric Dentistry, College of Dentistry, Yonsei University, Seoul, Republic of Korea \\ ${ }^{2}$ Oral Science Research Center, College of Dentistry, Yonsei University, Seoul, Republic of Korea \\ ${ }^{3}$ Department of Oral Biology, Division of Histology, College of Dentistry, Yonsei University, Seoul, Republic of Korea \\ Correspondence should be addressed to Jae-Ho Lee; leejh@yuhs.ac
}

Received 17 March 2016; Accepted 10 August 2016

Academic Editor: Werner Geurtsen

Copyright (C) 2016 Chung-Min Kang et al. This is an open access article distributed under the Creative Commons Attribution License, which permits unrestricted use, distribution, and reproduction in any medium, provided the original work is properly cited.

The aim of this study was to compare the differential gene expression and stemness in the human gingiva and dental follicles (DFs) according to their biological characteristics. Gingiva $(n=9)$ and DFs $(n=9)$ were collected from 18 children. Comparative gene expression profiles were collected using cDNA microarray. The expression of development, chemotaxis, mesenchymal stem cells (MSCs), and induced pluripotent stem cells (iPSs) related genes was assessed by quantitative reverse transcription-polymerase chain reaction (qRT-PCR). Histological analysis was performed using hematoxylin-eosin and immunohistochemical staining. Gingiva had greater expression of genes related to keratinization, ectodermal development, and chemotaxis whereas DFs exhibited higher expression levels of genes related to tooth and embryo development. qRT-PCR analysis showed that the expression levels of iPSc factors including SOX2, KLF4, and C-MYC were 58.5 $\pm 26.3,12.4 \pm 3.5$, and $12.2 \pm 1.9$ times higher in gingiva and VCAM1 (CD146) and ALCAM (CD166) were $33.5 \pm 6.9$ and $4.3 \pm 0.8$ times higher in DFs. Genes related to MSCs markers including CD13, CD34, CD73, CD90, and CD105 were expressed at higher levels in DFs. The results of qRT-PCR and IHC staining supported the microarray analysis results. Interestingly, this study demonstrated transcription factors of iPS cells were expressed at higher levels in the gingiva. Given the minimal surgical discomfort and simple accessibility, gingiva is a good candidate stem cell source in regenerative dentistry.

\section{Introduction}

Tissue engineering using mesenchymal stem cells (MSCs) is one of the most promising therapeutic strategies because MSCs have a high proliferation potential and may be manipulated to permit differentiation before transplantation $[1,2]$ To date, different human dental stem cells have been isolated from dental pulp stem cells (DPSCs) [3], stem cells from exfoliated deciduous teeth (SHED) [4], periodontal ligament (PDL) stem cells [5], stem cells from apical papilla (SCAP) [6], and dental follicle precursor cells (DFPCs) [7]. Recently, mounting evidence suggests that gingiva derived mesenchymal stem cells were isolated and characterized as having multilineage differentiation capacity and immunomodulatory properties [8]. The presence of stem cell populations in dental follicles and the gingiva was revealed recently, and the related gene expression patterns remain unclear.

The dental follicle (DF) tissue is a connective fibrous tissue sac surrounding the enamel organ and the dental papilla of the developing tooth germ [9]. The DF cells have been proposed to have the capacity to differentiate into periodontium consisting of cementum, alveolar bone, and PDL $[10,11]$. Despite an ectomesenchymal origin similar to that of the DFs, the gingiva appears to exhibit distinct functional activities during the maintenance of tissue integrity and during inflammatory responses [12]. It possesses a unique scarless healing process after wounding instead of the scar formation that is frequently observed in damaged extraoral tissues. So gingival tissue is postulated to have distinctive characteristics that 
accelerate wound closure, suggesting unique stemness with the ability to induce directed differentiation and regeneration.

Although some efforts were made to identify the genes that are differentially expressed in the periodontium [12-14], the genetic differences between the gingiva and DFs remain unknown. Given the anatomical and functional differences between the two tissues, it is reasonable to assume that there are also differences in the gene expression patterns. Thus, genetic investigation related to epithelial-mesenchyme interaction between gingiva and dental follicle can provide critical importance in regulating cell population and signaling system in the regeneration of periodontium. The aim of this study is to compare the gene expression patterns of the gingiva and DFs to enhance our understanding of the distinct regenerative ability in gingiva and tissue differentiation capacity in DFs.

\section{Materials and Methods}

The Institutional Review Board of the Yonsei University Dental Hospital approved the experimental protocol (approval number 2-2015-0005). All the subjects or their guardians have provided written informed consent. We used procedures similar to that recently applied by Song et al. [15] and Lee et al. [14].

2.1. Tissue Sampling and RNA Isolation. Gingival tissues were collected from children $(n=9)$ (5 males and 4 females, aged 7-12 years) with a healthy gingiva who underwent surgical gingival resection for the extraction of a supernumerary tooth, for odontoma, or for orthodontic reasons. The DF tissues were obtained from children $(n=9)$ ( 6 males and 3 females, aged 6-8 years), and they were separated from the coronal portion of the tooth during the extraction of supernumerary teeth. In DF, a piece of gingival tissue around the extraction socket was carefully curetted. These samples were immediately frozen and stored in liquid nitrogen. We used fresh tissue instead of cultured cells because, at the tissue level, gene expression reflects simultaneous profiles of many genes and can provide additional insights into the physiological processes or tissue-specific functions that are mediated by the coordinated action of sets of genes. Gingiva and DFs were immediately submerged in RLT buffer, which is a component of the RNeasy Fibrous Mini kit ${ }^{\circledR}$ (Qiagen, CA, USA). Prior to the RNA extraction, the tissues in RLT buffer were homogenized using a Bullet Blender ${ }^{\circledR}$ Bead (Next Advanced, Inc., NY, USA). Total RNA was extracted from gingiva and DFs using the RNeasy Fibrous Mini kit (Qiagen, USA) according to the manufacturer's instructions. The extracted RNA was eluted in $25 \mu \mathrm{L}$ of sterile water. RNA concentrations were measured from absorbance values at a wavelength of $260 \mathrm{~nm}$ using a spectrophotometer (NanoDrop ND-2000, Thermo Scientific, IL, USA). The RNA samples used in this study had 260/280 ratios of at least 1.8 .

2.2. cDNA Microarray Construction and Data Analysis. Global gene expression analyses were performed using Affymetrix Gene Chip ${ }^{\circledR}$ Human Gene 1.0 ST oligonucleotide arrays (Affymetrix Inc., CA, USA). The average amount of RNA isolated from the gingiva and DFs was $1 \mu \mathrm{g}$. As recommended by the manufacturer's protocol, $300 \mathrm{ng}$ of total RNA from each sample was converted to doublestranded cDNA. The cDNA was regenerated via randomprimed reverse transcription using a dNTP mix containing dUTP. The fragmented, end-labeled cDNA was hybridized to the Gene Chip ${ }^{\circledR}$ Human Gene 1.0 ST array for 16 hours at $45^{\circ} \mathrm{C}$ and $60 \mathrm{rpm}$ with a terminal transferase reaction incorporating a biotinylated dideoxynucleotide. After hybridization, the chips were stained and washed in a Genechip Fluidics Station $450^{\circledR}$ (Affymetrix) and scanned using a Genechip Array scanner $3000 \mathrm{G}^{\circledR}$ (Affymetrix). To determine whether genes were differentially expressed between the separated tissue groups, a one-way ANOVA was performed on the Robust Multi-Average (RMA) expression values. A multiple testing correction was applied to the $p$ values of the $F$-statistics to adjust the false discovery rate. Genes with adjusted $F$ statistic $p$ values $<0.05$ were extracted. Genes that were highly expressed in the gingiva or DFs and that exhibited differences greater than 4 -fold between the signal value of the control and the test group were selected for further study. These genes were then classified based on the information related to gene function that is available in Gene Ontology from the KEGG Pathway database (http://david.abcc.ncifcrf.gov/home.jsp). This microarray data set was approved by the Gene Expression Omnibus (GEO) (http://www.ncbi.nlm.nih.gov/geo/); the GEO accession numbers of the data set are GSE58480 (gingiva) and GSE51342 (dental follicle).

2.3. Quantitative RT-PCR. The single-stranded cDNA required for the polymerase chain reaction (PCR) analysis was produced using $500 \mathrm{ng}$ of extracted total RNA as a template for reverse transcription (RT) (Superscript III Reverse Transcriptase and random primer, Invitrogen, UK). The RT reaction was incubated at $65^{\circ} \mathrm{C}$ for 5 minutes, then $25^{\circ} \mathrm{C}$ $(5 \mathrm{~min}), 50^{\circ} \mathrm{C}(1 \mathrm{hr})$, and $70^{\circ} \mathrm{C}(15 \mathrm{~min})$ to inactivate the activity of the reverse transcriptase. The synthesized cDNA was diluted 1:10 in distilled water and used as a template for quantitative RT-PCR using the ABI7300 RT-PCR system (Applied Biosystems, Warrington, UK). The samples were prepared in triplicate with a volume of $25 \mu \mathrm{L}$ containing $1 \mathrm{x}$ Universal TaqMan Master Mix (4369016, Applied Biosystems), the PCR primers at $0.9 \mu \mathrm{M}$, and the diluted cDNA. The amplification conditions were $50^{\circ} \mathrm{C}$ for 2 minutes and $95^{\circ} \mathrm{C}$ for 10 minutes, followed by 40 cycles of $95^{\circ} \mathrm{C}$ for 15 seconds and $60^{\circ} \mathrm{C}$ for 1 minute. The following TaqMan gene expression assay primers (Applied Biosystems) were used: KRT6A, CXCL10, CSTA, AMBN, ADAM12, CXCL12, cMYC, KLF4, SOX2, CD106 (VCAM1), CD166 (ALCAM), and 18S rRNA. We selected known genes that are representative of the two tissues and little-known genes that are involved in their physiological functions.

ABI 7300 SDS 1.3.1 software (Applied Biosystems) recorded the fluorescence intensity of the reporter and quencher dyes, and results are plotted versus time, represented by the cycle number. The amplification plots were examined during the early log phase of product accumulation 
TABLE 1: Specific primer used for quantitative RT-PCR analysis.

\begin{tabular}{|c|c|c|c|}
\hline Gene symbol & Functions & Assay ID & Product size (bp) \\
\hline KRT6A & $\begin{array}{l}\text { Ectoderm development, positive regulation of cell } \\
\text { proliferation, cell differentiation }\end{array}$ & Hs01699178_g1 & 83 \\
\hline CXCL10 & Positive regulation of leukocyte, chemotaxis & Hs01124251_g1 & 135 \\
\hline CSTA & $\begin{array}{l}\text { Keratinocyte differentiation, negative regulation of } \\
\text { peptidase activity }\end{array}$ & Hs00193257_m1 & 114 \\
\hline AMBN & $\begin{array}{l}\text { Cell proliferation, bone mineralization, odontogenesis } \\
\text { of dentin-containing tooth }\end{array}$ & Hs00212970_ml & 61 \\
\hline ADAM12 & $\begin{array}{l}\text { Cell-cell and cell-matrix interactions, including } \\
\text { fertilization, muscle development, neurogenesis }\end{array}$ & Hs01106101_ml & 54 \\
\hline CXCL12 & $\begin{array}{l}\text { Immune response, positive regulation of monocyte } \\
\text { chemotaxis }\end{array}$ & Hs03676656_mH & 88 \\
\hline C-MYC & Regulation of transcription, DNA-dependent & Hs00153408_ml & 107 \\
\hline KLF4 & $\begin{array}{l}\text { Mesodermal cell fate determination, negative regulation } \\
\text { of cell proliferation, regulation of transcription }\end{array}$ & Hs00358836_ml & 110 \\
\hline SOX 2 & $\begin{array}{l}\text { Negative regulation of transcription from RNA } \\
\text { polymerase II promoter, osteoblast differentiation }\end{array}$ & Hs01053049_s1 & 91 \\
\hline CD106 & $\begin{array}{l}\text { Response to hypoxia, acute inflammatory response, } \\
\text { chronic inflammatory response }\end{array}$ & Hs01003372_m1 & 62 \\
\hline CD166 & $\begin{array}{l}\text { Cell adhesion, signal transduction, motor axon } \\
\text { guidance }\end{array}$ & Hs00977641_ml & 103 \\
\hline 18S rRNA & & Hs03003631_g1 & 69 \\
\hline
\end{tabular}

above background (the threshold cycle number, $\mathrm{Ct}$ ) to obtain a precise quantification of initial target. The $\mathrm{Ct}$ values (the threshold cycle $(\mathrm{Ct})$ number) were subsequently used to determine $\Delta \mathrm{Ct}$ values ( $\Delta \mathrm{Ct}=\mathrm{Ct}$ of the gene minus $\mathrm{Ct}$ of the $18 \mathrm{~S}$ rRNA control). Relative expressions were expressed as the relative change by applying the equation $2^{-\Delta \Delta \mathrm{Ct}}(\Delta \Delta \mathrm{Ct}$; differences in $\Delta \mathrm{Ct}$ values). All these quantitative RT-PCR procedures were done obtaining triplicated data. The results were analyzed using SPSS 20 software (SPSS Inc., IL, USA). Statistical differences were calculated by Mann-Whitney $U$ tests, and $p<0.05$ was considered statistically significant. The specific primer assay ID and product sizes for each gene are listed in Table 1.

2.4. Immunohistochemical Staining. For immunohistochemical staining, gingival tissue and DF tissue were fixed in $10 \%$ buffered formalin for 1 day, embedded in paraffin, and then sectioned at a thickness of $3 \mu \mathrm{m}$. The specimens were subjected to IHC staining with antibodies specific for CXCL10 (rabbit polyclonal, diluted 1:50; Ab9807, Abcam, Cambridge, UK), CSTA (rabbit polyclonal, diluted 1:2,000; Ab61223, Abcam), AMBN (rabbit polyclonal, diluted 1:200; Ab116347, Abcam), and CXCL12 (rabbit polyclonal, diluted 1:50; Ab9797, Abcam). Endogenous peroxidase activity was quenched via addition of $3 \%$ hydrogen peroxide. The sections were incubated in $5 \%$ bovine serum albumin to block nonspecific binding. The primary antibodies were diluted to facilitate optimal staining, and the sections were incubated overnight. After incubation, EnVision+ System HRP-Labeled Polymer anti-rabbit (K4003, Dako North America, Inc., CA, USA) was applied for $20 \mathrm{~min}$. Color development was performed using labeled streptavidin biotin kits (Dako) according to the manufacturer's instructions.

\section{Results}

3.1. Gene Expression Profiles of the Gingiva and Dental Follicles. 1,182 out of 33,297 (3.6\%) genes exhibited an absolute expression change of at least 4 -fold. The expression levels of 555 genes were 4-fold higher in the gingiva than in DFs, while the expression levels of 627 genes were at least 4fold higher in DFs than in the gingiva. The overall data distribution and frequency were confirmed by density and box plots of the ratio of the standardized log intensity to the average intensity. Ultimately, 829 genes were analyzed further, with the exception of several genes with unknown biological functions. The data were further filtered, and the genes are listed in Tables 2 and 3 according to their relative biological functions. In the gingiva, the expression levels of 387 genes were upregulated by 4 -fold or more in comparison to DFs, while the expression levels of 442 genes were upregulated by 4 -fold in DFs in comparison to the gingiva.

3.2. Gene Ontology Analysis. To identify the biological functions and features of the selected genes, the expression data sets were organized into Gene Ontology Consortium (GO) groups using the DAVID web-based tool. These genes were then classified based on information regarding gene function in gene ontology from the KEGG Pathway database. Figure 1 shows GO classes for the two data sets analyzed ( $F$-statistic $p<0.05)$. 
TABLE 2: Representative genes differentially expressed with higher expression levels in the gingiva than in dental follicles (absolute fold change $>4.0$ ).

\begin{tabular}{|c|c|c|c|c|c|}
\hline Functional category & Gene symbol & Biological process & Accession number & Absolute fold change & Standard deviation \\
\hline \multirow{4}{*}{$\begin{array}{l}\text { Metabolism and } \\
\text { catabolism }\end{array}$} & LIPK & Lipid catabolic process & NM_001080518 & 90.99 & 11.87 \\
\hline & FMO2 & Organic acid metabolic process & NM_001460 & 34.26 & 7.05 \\
\hline & ARG1 & Arginine catabolic process & NM_000045 & 18.91 & 5.06 \\
\hline & LIPN & Lipid catabolic process & NM_001080518 & 13.27 & 4.19 \\
\hline \multirow{5}{*}{$\begin{array}{l}\text { Protein modification } \\
\text { and maintenance }\end{array}$} & KLK7 & Proteolysis & NM_139277 & 30.47 & 6.52 \\
\hline & KLK10 & Proteolysis & NM_002776 & 28.97 & 6.34 \\
\hline & KLK6 & Protein autoprocessing & NM_002774 & 25.58 & 6.10 \\
\hline & TGM1 & Protein modification process & NM_000359 & 22.21 & 5.48 \\
\hline & OCLN & Protein complex assembly & NM_002538 & 12.48 & 4.48 \\
\hline \multirow{8}{*}{ Structural process } & SPRR2A & Keratinization & NM_005988 & 207.84 & 18.61 \\
\hline & KRT1 & Keratinization & NM_006121 & 146.08 & 15.41 \\
\hline & CNFN & Keratinization & NM_032488 & 74.92 & 10.64 \\
\hline & CSTA & Keratinocyte differentiation & NM_005213 & 69.63 & 10.22 \\
\hline & KRT4 & Cytoskeleton organization & NM_002272 & 39.48 & 7.50 \\
\hline & KRT3 & Cytoskeleton organization & NM_057088 & 36.71 & 7.23 \\
\hline & FLG & Keratinocyte differentiation & NM_002016 & 24.31 & 5.75 \\
\hline & DSP & Keratinocyte differentiation & NM_004415 & 17.15 & 5.22 \\
\hline \multirow{4}{*}{ Transport activity } & CLCA4 & Ion transport & NM_012128 & 48.96 & 8.48 \\
\hline & AQP3 & Water transport & NM_004925 & 27.74 & 6.41 \\
\hline & SLC5A1 & Transmembrane transport & NM_000343 & 19.52 & 5.09 \\
\hline & GLTP & Glycolipid transport & NM_016433 & 7.56 & 3.04 \\
\hline \multirow{8}{*}{$\begin{array}{l}\text { Developmental } \\
\text { process }\end{array}$} & KRT10 & Epidermis development & NM_000421 & 152.93 & 15.74 \\
\hline & SCEL & Epidermis development & NM_144777 & 134.38 & 14.68 \\
\hline & KRT6B & Ectoderm development & NM_005555 & 90.30 & 12.11 \\
\hline & KRT6A & Ectoderm development & NM_005554 & 57.61 & 9.64 \\
\hline & SPINK5 & Epidermal cell differentiation & NM_001127698 & 55.60 & 9.34 \\
\hline & EHF & Epithelial cell differentiation & NM_012153 & 14.27 & 5.50 \\
\hline & SOX2 & Embryonic development & NM_003106 & 8.67 & 3.34 \\
\hline & TUFT1 & Odontogenesis & NM_020127 & 7.87 & 3.19 \\
\hline \multirow{5}{*}{ Physiologic process } & RHCG & Regulation of $\mathrm{pH}$ & NM_016321 & 51.23 & 8.68 \\
\hline & ABCA12 & Cellular homeostasis & NM_173076 & 39.33 & 7.55 \\
\hline & EREG & Angiogenesis & NM_001432 & 13.04 & 4.29 \\
\hline & NMU & Gastric acid secretion & NM_006681 & 12.72 & 4.05 \\
\hline & SCD & Oxidation reduction & NM_005063 & 4.35 & 2.25 \\
\hline \multirow{3}{*}{$\begin{array}{l}\text { Nucleic acid synthesis } \\
\text { and modification }\end{array}$} & MACC1 & Regulation of cell division & NM_182762 & 20.30 & 5.38 \\
\hline & ESRP1 & mRNA processing & NM_017697 & 17.02 & 5.85 \\
\hline & HIST1H1B & Nucleosome assembly & NM_005322 & 6.85 & 2.91 \\
\hline \multirow{3}{*}{$\begin{array}{l}\text { Signal transduction } \\
\text { and regulation }\end{array}$} & IL1F9 & Cell-cell signaling & NM_019618 & 26.31 & 6.03 \\
\hline & ARAP2 & Signal transduction & NM_015230 & 9.88 & 3.89 \\
\hline & DAPP1 & Signal transduction & NM_014395 & 8.90 & 3.32 \\
\hline \multirow{4}{*}{ Apoptosis } & MAL & Induction of apoptosis & NM_002371 & 49.41 & 8.48 \\
\hline & ALOX12 & Antiapoptosis & NM_000697 & 31.70 & 6.69 \\
\hline & FAM3B & Apoptosis & NM_058186 & 27.28 & 6.16 \\
\hline & BNIPL & Apoptosis & NM_001159642 & 18.88 & 5.01 \\
\hline
\end{tabular}


TABLE 2: Continued.

\begin{tabular}{|c|c|c|c|c|c|}
\hline Functional category & Gene symbol & Biological process & Accession number & Absolute fold change & Standard deviation \\
\hline \multirow{5}{*}{ Cell adhesion } & CLDN17 & Cell-cell adhesion & NM_012131 & 91.67 & 11.90 \\
\hline & CRNN & Cell-cell adhesion & NM_016190 & 71.09 & 10.39 \\
\hline & DSC3 & Homophilic cell adhesion & NM_024423 & 27.40 & 6.38 \\
\hline & CDSN & Cell adhesion & NM_001264 & 26.60 & 5.80 \\
\hline & DSG3 & Cell adhesion & NM_001944 & 23.82 & 7.07 \\
\hline \multirow{4}{*}{$\begin{array}{l}\text { Cell cycle and } \\
\text { transcriptional } \\
\text { regulation }\end{array}$} & GRHL1 & Regulation of transcription & NM_198182 & 31.32 & 6.62 \\
\hline & IRF6 & Cell cycle arrest & NM_006147 & 13.05 & 4.87 \\
\hline & CASZ1 & Regulation of transcription & NM_001079843 & 4.29 & 2.27 \\
\hline & E2F8 & Regulation of transcription & NM_024680 & 4.20 & 2.21 \\
\hline \multirow{5}{*}{$\begin{array}{l}\text { Immune and } \\
\text { inflammatory process }\end{array}$} & SERPINB4 & Immune response & NM_002974 & 73.33 & 10.65 \\
\hline & IL1F6 & Inflammatory response & NM_014440 & 43.13 & 7.87 \\
\hline & IL1RN & Inflammatory response & NM_173842 & 26.09 & 6.48 \\
\hline & IL1A & Inflammatory response & NM_000575 & 23.93 & 5.74 \\
\hline & CD1A & Immune response & NM_001763 & 4.16 & 2.19 \\
\hline \multirow{4}{*}{$\begin{array}{l}\text { Cytokine and } \\
\text { chemokine activity }\end{array}$} & CXCL17 & Chemotaxis & NM_198477 & 11.34 & 3.83 \\
\hline & CCL21 & Chemotaxis & NM_002989 & 6.25 & 2.78 \\
\hline & ANLN & Cytokinesis & NM_018685 & 5.84 & 2.63 \\
\hline & CXCL10 & Chemotaxis & NM_001565 & 4.29 & 2.37 \\
\hline
\end{tabular}

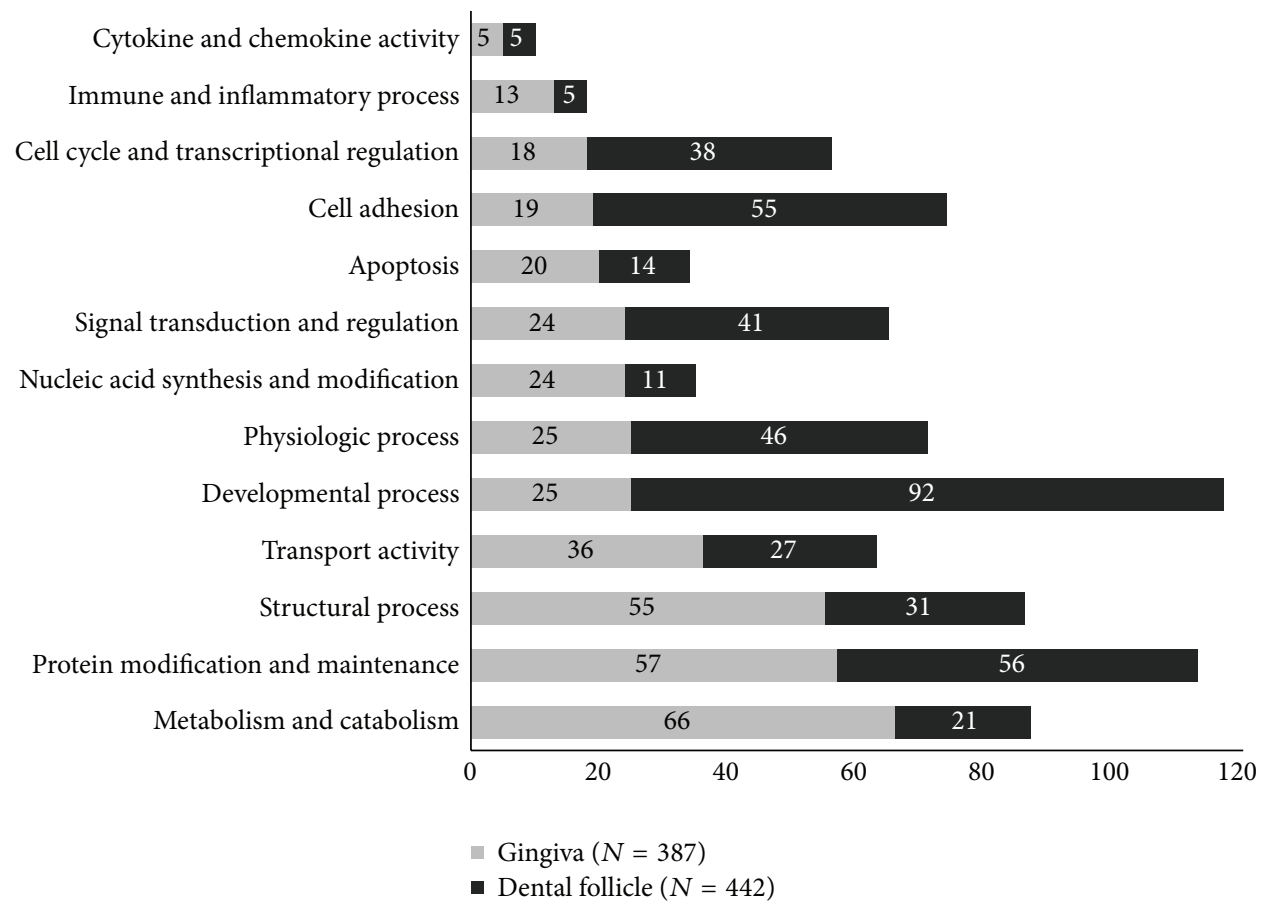

FIGURE 1: Main categories of genes expressed in the gingiva and dental follicles according to biological process. $x$-axis: the number of involved genes.

A total of 66 genes encoding metabolic and catabolic process were expressed more abundantly in the gingiva than in the DFs. Fifty-five genes related to structural processes such as keratinization and cytoskeleton organization were expressed at higher levels in the gingiva. On the other hand, 92 developmental process-related genes were highly expressed in DFs as a result of biological processes including odontogenesis, ossification, and bone mineralization. Cell cycle-associated genes and signal transduction- and regulation-related genes were expressed at higher levels in DFs. These results are consistent with the occurrence of higher proliferation rates in DFs. 
TABLE 3: Representative genes differentially expressed with higher expression levels in dental follicles than in the gingiva (absolute fold change $>4.0$ ).

\begin{tabular}{|c|c|c|c|c|c|}
\hline Functional category & Gene symbol & Biological process & Accession number & Absolute fold change & Standard deviation \\
\hline \multirow{4}{*}{$\begin{array}{l}\text { Metabolism and } \\
\text { catabolism }\end{array}$} & ALDH1L2 & Carbon metabolic process & NM_001034173 & 19.63 & 5.13 \\
\hline & MOXD1 & Histidine catabolic process & NM_015529 & 17.92 & 4.91 \\
\hline & ELOVL2 & Fatty acid metabolic process & NM_017770 & 12.62 & 4.07 \\
\hline & FBXL7 & Protein catabolic process & NM_012304 & 8.58 & 3.27 \\
\hline \multirow{6}{*}{$\begin{array}{l}\text { Protein modification } \\
\text { and maintenance }\end{array}$} & ADAM12 & Metalloendopeptidase activity & NM_003474 & 37.09 & 7.25 \\
\hline & MMP16 & Metalloendopeptidase activity & NM_005941 & 24.32 & 5.82 \\
\hline & MMP2 & Metalloendopeptidase activity & NM_004530 & 19.64 & 5.17 \\
\hline & MMP8 & Metalloendopeptidase activity & NM_002424 & 11.86 & 3.89 \\
\hline & MMP13 & Metalloendopeptidase activity & NM_002427 & 7.60 & 3.16 \\
\hline & ADAM22 & Proteolysis & NM_021723 & 5.97 & 2.75 \\
\hline \multirow{4}{*}{ Structural process } & COL11A1 & Extracellular matrix organization & NM_001854 & 29.15 & 6.38 \\
\hline & MAP1B & Microtubule bundle formation & NM_005909 & 10.30 & 3.61 \\
\hline & FBN2 & Anatomical structure morphogenesis & NM_001999 & 9.02 & 3.40 \\
\hline & LUM & Collagen fibril organization & NM_002345 & 8.68 & 3.32 \\
\hline \multirow{5}{*}{ Transport activity } & KCNT2 & Ion transport & NM_198503 & 11.30 & 3.80 \\
\hline & ABCC9 & Potassium ion transport & NM_005691 & 11.18 & 3.77 \\
\hline & RHOBTB3 & Retrograde transport & NM_014899 & 10.62 & 3.72 \\
\hline & SLC4A4 & Sodium ion transport & NM_001098484 & 10.12 & 3.68 \\
\hline & HEPH & Copper ion transport & NM_138737 & 8.34 & 3.28 \\
\hline \multirow{13}{*}{$\begin{array}{l}\text { Developmental } \\
\text { process }\end{array}$} & AMBN & Odontogenesis & NM_016519 & 117.54 & 16.99 \\
\hline & CDH11 & Ossification & NM_001797 & 38.12 & 7.40 \\
\hline & ALPL & Biomineral tissue development & NM_000478 & 33.21 & 6.83 \\
\hline & ASPN & Bone mineralization & NM_017680 & 33.05 & 6.85 \\
\hline & FGF7 & Embryonic development & NM_002009 & 29.53 & 6.44 \\
\hline & COL1A2 & Skeletal system development & NM_000089 & 14.50 & 4.41 \\
\hline & RUNX2 & Ossification & NM_001024630 & 13.85 & 4.23 \\
\hline & PDGFRB & Embryonic development & NM_002609 & 11.85 & 3.93 \\
\hline & WNT2 & Mesenchymal cell proliferation & NM_003391 & 10.28 & 3.73 \\
\hline & BMP5 & Ossification & NM_021073 & 7.13 & 3.28 \\
\hline & LEF1 & Wnt receptor signaling pathway & NM_016269 & 5.83 & 2.66 \\
\hline & PAX3 & Organ morphogenesis & NM_181457 & 4.70 & 2.38 \\
\hline & MSX1 & Organ morphogenesis & NM_002448 & 4.23 & 2.24 \\
\hline \multirow{4}{*}{ Physiologic process } & VAT1L & Oxidation reduction & NM_020927 & 12.30 & 3.98 \\
\hline & TFPI & Blood coagulation & NM_006287 & 9.49 & 3.49 \\
\hline & TPM1 & Muscle contraction & NM_000366 & 8.78 & 3.30 \\
\hline & SOBP & Sensory perception & NM_018013 & 8.27 & 3.21 \\
\hline \multirow{3}{*}{$\begin{array}{l}\text { Nucleic acid synthesis } \\
\text { and modification }\end{array}$} & EYA4 & DNA repair & NM_004100 & 24.90 & 5.86 \\
\hline & NAP1L3 & Nucleosome assembly & NM_004538 & 16.47 & 4.68 \\
\hline & SNRPN & RNA splicing & BC043194 & 5.05 & 1.58 \\
\hline \multirow{4}{*}{$\begin{array}{l}\text { Signal transduction } \\
\text { and regulation }\end{array}$} & PDE7B & Signal transduction & NM_018945 & 22.99 & 5.59 \\
\hline & CHN1 & Signal transduction & NM_018945 & 22.98 & 5.60 \\
\hline & LIFR & Cytokine-mediated signaling pathway & NM_002310 & 8.78 & 3.31 \\
\hline & FSTL1 & BMP signaling pathway & NM_007085 & 8.75 & 3.31 \\
\hline \multirow{4}{*}{ Apoptosis } & SEMA3A & Apoptosis & NM_006080 & 51.87 & 8.72 \\
\hline & PEG10 & Apoptosis & NM_015068 & 21.89 & 5.43 \\
\hline & SULF1 & Apoptosis & NM_001128205 & 11.18 & 3.77 \\
\hline & NELL1 & Induction of apoptosis & NM_006157 & 8.67 & 3.27 \\
\hline
\end{tabular}


TABLE 3: Continued.

\begin{tabular}{|c|c|c|c|c|c|}
\hline Functional category & Gene symbol & Biological process & Accession number & Absolute fold change & Standard deviation \\
\hline \multirow{3}{*}{ Cell adhesion } & $\mathrm{OMD}$ & Cell adhesion & NM_005014 & 40.83 & 7.69 \\
\hline & VCAN & Cell adhesion & NM_004385 & 35.76 & 7.25 \\
\hline & SPON1 & Cell adhesion & NM_006108 & 32.63 & 6.78 \\
\hline \multirow{3}{*}{$\begin{array}{l}\text { Cell cycle and } \\
\text { transcriptional } \\
\text { regulation }\end{array}$} & MYEF2 & Transcription & NM_016132 & 6.71 & 2.88 \\
\hline & SYCP2 & Cell cycle & NM_014258 & 5.41 & 2.53 \\
\hline & АРBB2 & Cell cycle arrest & NM_004307 & 5.25 & 2.49 \\
\hline \multirow{5}{*}{$\begin{array}{l}\text { Immune and } \\
\text { inflammatory process }\end{array}$} & TPST1 & Inflammatory response & NM_003596 & 9.00 & 3.34 \\
\hline & PXDN & Immune response & NM_012293 & 8.89 & 3.40 \\
\hline & IFI44L & Immune response & NM_006820 & 6.01 & 2.79 \\
\hline & PECAM1 & Phagocytosis & NM_000442 & 4.26 & 2.25 \\
\hline & COLEC12 & Phagocytosis, recognition & NM_130386 & 4.23 & 2.22 \\
\hline \multirow{5}{*}{$\begin{array}{l}\text { Cytokine and } \\
\text { chemokine activity }\end{array}$} & CXCL12 & Chemotaxis & NM_000609 & 11.04 & 3.79 \\
\hline & SLIT3 & Chemotaxis & NM_003062 & 8.94 & 3.34 \\
\hline & СMTM3 & Chemotaxis & NM_144601 & 5.24 & 2.52 \\
\hline & STX2 & Cytokinesis & NM_194356 & 4.39 & 2.27 \\
\hline & CCR1 & Chemotaxis & NM_001295 & 4.31 & 2.36 \\
\hline
\end{tabular}

3.3. Confirmation of Gene Differential Expression Using Quantitative RT-PCR. Quantitative RT-PCR analysis verified the cDNA microarray results. Six genes for which the difference in expression levels between the gingiva and DFs was at least 4 -fold were selected. Mann-Whitney " $U$ " test was performed to correlate the relative change with differential expression as detected by PCR. The expression levels of KRT6A, CSTA, and CXCL10 were $13406.7 \pm 14962.8,1524.4 \pm 714.8$, and $4.7 \pm 2.0$ times higher in gingiva, and $A M B N, A D A M 12$, and CXCL12 were $20585.4 \pm 24267.0,192.5 \pm 66.5$, and $66.0 \pm 6.5$ times higher in DFs (Figure 2). These results were consistent with the microarray results.

3.4. Verification of Array Results by Immunohistochemical Staining. The following four proteins were the targets of the IHC study: CXCL10, CSTA, AMBN, and CXCL12 (Figure 3). CXCL10 was broadly stained in the epithelial area of the gingiva. CSTA was strongly stained in all of the layers of the gingiva. $A M B N$ was not stained in the gingiva but stained around the outer area of the DFs. CXCL12 was stained in a single cellular layer and in the collagenous connective tissue of DFs. The results were consistent with those of the cDNA microarray analysis at the protein level.

3.5. Stemness Characterization by Surface Protein Markers. Based on previous studies, dental stem cells were characterized using surface protein markers $[16,17]$. The comparative expression results for stem cell marker genes are listed in Figure 4(a). Our results indicated that DF tissue derived MSCs are a cell population that is more positive for mesenchymal MSC markers (including CD13, CD34, CD73, $C D 90$, and CD105) according to the International Society for Cell Therapy [18]. The comparative expression of four induced pluripotent stem cells (iPSCs) marker genes (i.e., OCT-3, 4, SOX2, cMYC, and KLF4) were expressed at higher levels in the gingiva. As a result of qRT-PCR, SOX2, KLF4,

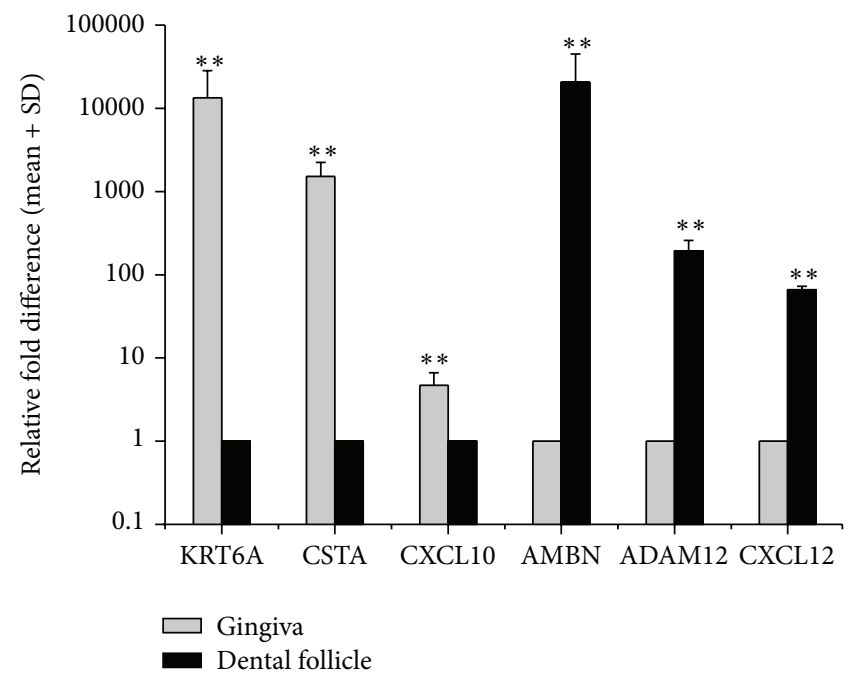

FIGURE 2: The relative difference in mRNA expression of six differentially expressed genes between the gingiva and dental follicles using quantitative RT-PCR. The data are presented as the mean + standard deviation and expressed as the relative change by applying the equation $2^{-\Delta \Delta \mathrm{Ct}}$. $y$-axis: a log scale measure. ${ }^{* *} p<0.05$.

and $c M Y C$ appeared 58.5, 12.43, and 12.23 times higher from the gingiva and VCAM1 (CD106) and ALCAM (CD166) were 33.54 and 4.27 times higher in DFs (Figure 4(b)). However, OCT-3, 4 did not show a clear difference in comparison to the other markers (0.46-fold difference).

\section{Discussion}

In this study, a cDNA microarray comparison analysis was performed to focus on differences in the gene expression profiles of gingiva and DFs in children. The majority of 


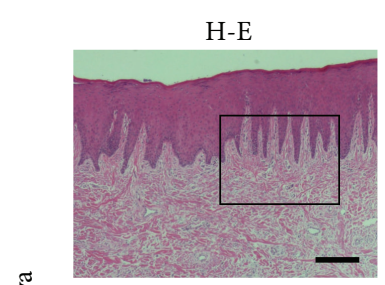

(a)

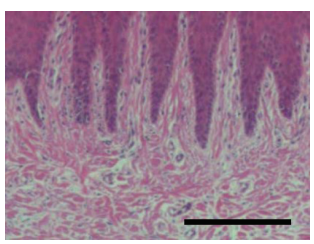

(f)

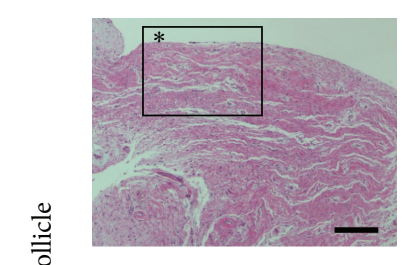

(k)

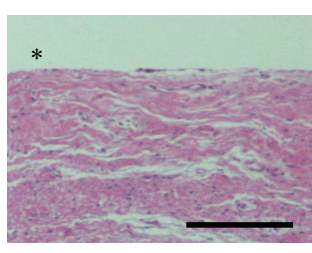

(p)

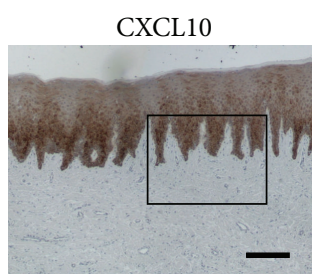

(b)

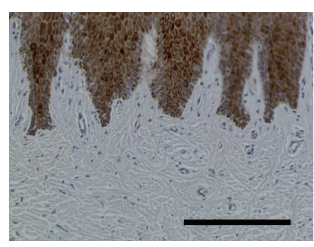

(g)

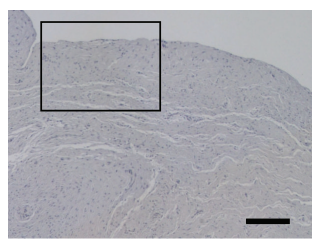

(1)

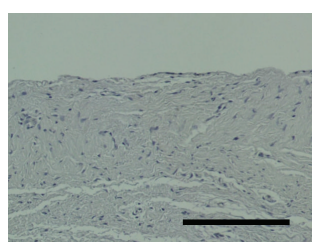

(q)

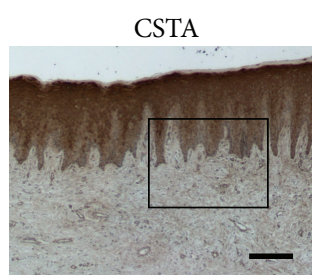

(c)

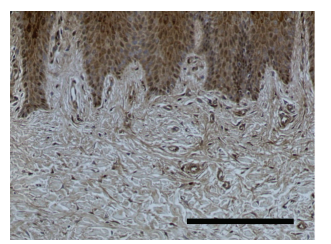

(h)

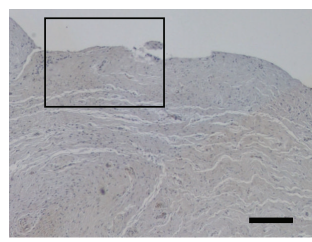

(m)

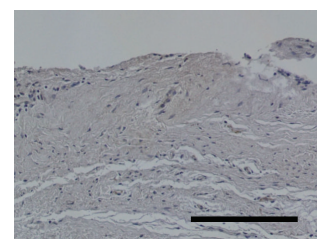

(r)

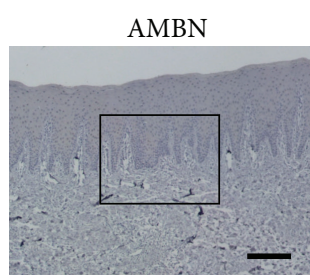

(d)

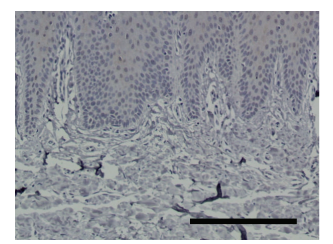

(i)

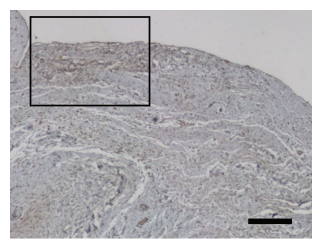

(n)

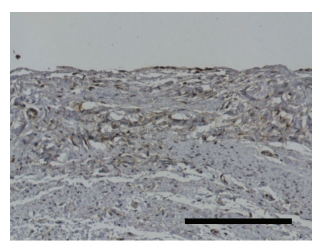

(s)

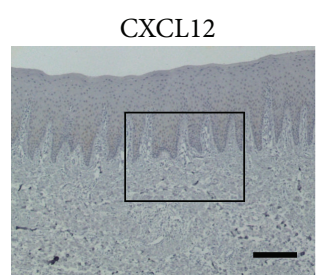

(e)

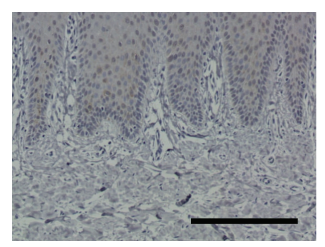

(j)

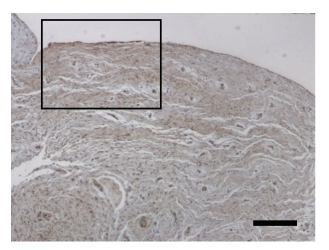

(o)

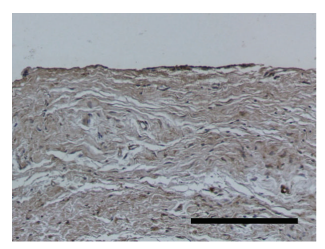

$(\mathrm{t})$

Scale bars: $200 \mu \mathrm{m}$

FIGURE 3: Verification of microarray results by immunohistochemical (IHC) staining. Hematoxylin-eosin staining in the gingiva (a, f) and dental follicles (DFs) (k, p) (asterisk: outer border neighboring alveolar bone). IHC staining for CXCL10 in the gingiva (b, g) and DFs (1, q). IHC staining for CSTA in the gingiva $(\mathrm{c}, \mathrm{h})$ and DFs $(\mathrm{m}, \mathrm{r})$. The expression of CXCL10 and CSTA was stained markedly in the gingival epithelium. The IHC staining for $A M B N$ in the gingiva (d, i) and DFs (, $\mathrm{s})$. AMBN was stained around the outer layer of the DFs. The IHC staining for CXCL12 in the gingiva $(\mathrm{e}, \mathrm{j})$ and dental follicles $(\mathrm{o}, \mathrm{t})$. CXCL12 was stained in both a cellular layer and the collagenous connective tissue of DFs (scale bars: $200 \mu \mathrm{m}$ ).

genes $(32,115$ out of $33,297,96.5 \%)$ showed similar expression level between the gingiva and DFs when using a 4-fold absolute change cutoff value. Most of those genes encoded cell adhesion proteins, proteins involved in structural processes, or proteins related to signal transduction and regulation. This finding suggests that the gingiva and DFs differentiate into different tissue later although they originate from an ectomesenchymal cell. This is likely due to the regulation of comparable intracellular signaling pathways. In contrast, approximately $4 \%$ of genes were differentially expressed above the selected threshold. While accounting for only a small portion of the whole gene array, these genes might contribute to the distinct biological functions and distinguish each other phenotypically and morphologically. To investigate this assumption, comparative gene expression was analyzed with respect to the biological functions of the genes.
In the gingiva, KRT1, CSTA, and FLG were expressed at significantly higher levels. The gingival epithelium is a stratified squamous keratinizing tissue, and these genes are related to keratinization or keratinocyte differentiation. KRT1 marks the cornification pathway of differentiation and is expressed in keratinized areas [19]. CSTA is one of the precursor proteins of the cornified cell envelope in keratinocytes and plays a role in epidermal development and maintenance [20]. FLG is essential for the regulation of epidermal homeostasis and interacts with keratin intermediate filaments [21]. Epidermis and ectoderm developmentrelated genes were strongly upregulated in the gingiva versus DFs. KRT6B and KRT6A were markedly upregulated in the gingiva, with 90.30- and 57.61-fold differential expression, respectively. These proteins are rapidly induced in wound-proximal epidermal keratinocytes after skin injury 


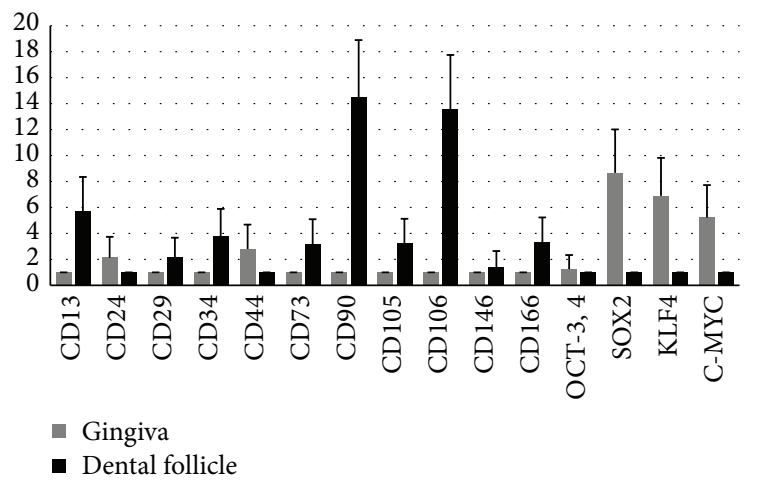

(a)

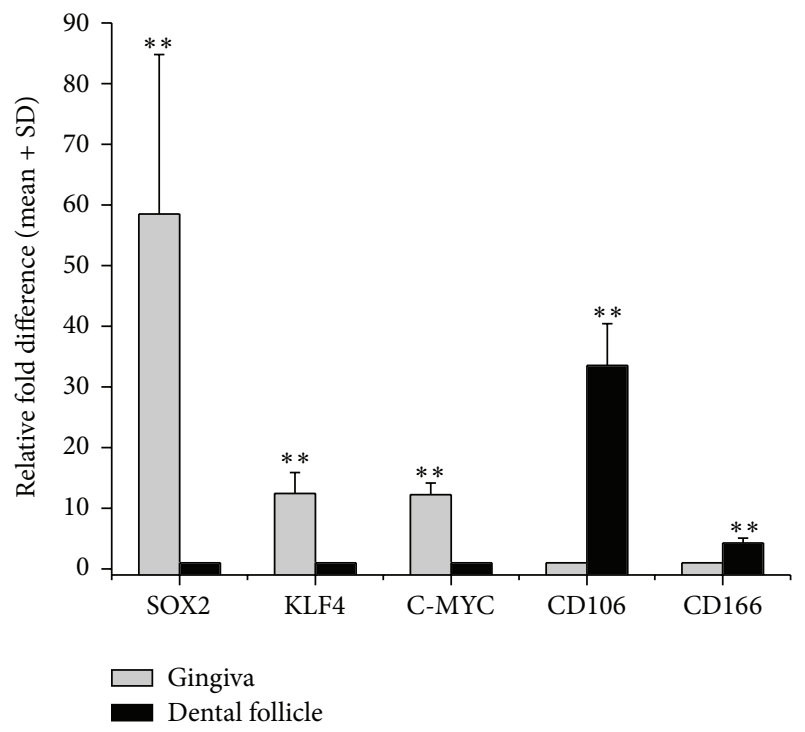

(b)

FIGURE 4: The relative gene expression of dental-derived stem cell and induced pluripotent stem cell markers using cDNA microarray (a). The relative fold difference in the expression of five stem cell marker genes between the gingiva and dental follicles using quantitative RT-PCR (b). The data are presented as the mean + standard deviation $(\mathrm{a}, \mathrm{b})$ and expressed as the relative change by applying the equation $2^{-\Delta \Delta \mathrm{Ct}}(\mathrm{b}) .{ }^{* *} p<0.05$.

and regulate the migratory potential of skin keratinocytes during wound repair [22]. SCEL may function in the assembly or regulation of proteins in the keratinized envelope [23]. The upregulation of these genes may indicate the existence of a fast turnover rate in the gingiva and may facilitate fibroblast proliferation, which is an important event for tissue repair.

The oral mucosa is affected by exposure to various extrinsic factors such as chemicals and microorganisms. Genes related to apoptosis and chemotaxis such as CXCL10, CXCL17, $A N L N$, and CCL21 were strongly expressed in the gingiva. CXCL10 is secreted by the keratinocytes and is a marker of the host immune response [24]. This chemokine plays an important role in the infiltration of Thl cells and affects the gingiva by exacerbating periodontal disease [25]. The overexpression of these chemokines might be associated with the generation and delivery of immune and inflammatory responses in the gingiva.

On the other hand, genes related to tooth and embryo development exhibited significantly higher expression in DFs. These results are consistent with those of a previous DF gene expression study that compared DFs to the PDL [14]. The increased expression of $A M B N$ indicates that DFs play an important role in enamel matrix formation and mineralization [26]. In this study, WNT2 and LEF1 were upregulated in DFs suggesting that DFs are involved in the complex interplay of signaling factors that regulate tooth initiation and morphogenesis $[27,28]$. Runx2 is a key regulator of osteoblast marker genes and promotes the differentiation of mesenchymal stem cells into osteoblasts. The literature indicates that Runx2 functions in the dental mesenchyme and mediates transduction signals from the dental epithelium to the mesenchyme during tooth development [29]. It also influences the molecular events that regulate tooth eruption-the most important physiologic role is likely being at the eruptive site [30]. Given the adaptive role of DFs, the presence of these genes suggests a central role of DFs in tooth formation.

Genes encoding protein modification- and signal transduction-related proteins tend to be expressed at higher levels in DFs than in the gingiva. The metalloprotease $A D A M$ 12 has been implicated in biological processes including fertilization and neurogenesis in DFs [11]. MMP-13 may be a major collagenolytic enzyme that degrades the extracellular matrix during tooth eruption. The upexpression of MMP-13 means DFs have important functions for the coordination of tooth eruption [31]. CXCL12 is a chemotactic factor for mesenchymal stem cells and mediates the suppressive effect of those cells on osteoclastogenesis. This factor can be expressed in DFs during tooth development including the epithelium surrounding the developing tooth bud [32].

To verify cDNA microarray results, six genes of different functions were selected for quantitative RT-PCR analyses. The expression levels of KRT6A, CSTA, and CXCL10 were upregulated in the gingiva; $A M B N, A D A M 12$, and CXCL12 were upregulated in DFs. These results were consistent with the microarray results. To better understand the roles of the differentially expressed genes, IHC analysis was performed to identify their functions at tissue level. CXCL10 and CSTA were strongly stained in all of the layers of the gingival tissue but were not stained in DFs. The genes that are highly expressed in the gingiva are stained in the epithelium because the prominent difference in structure between the gingiva and DFs is in the keratinized epithelium. AMBN and CXCL12 were broadly stained in the outer area of DFs especially in the reduced enamel epithelium.

Several cell populations with stem cells properties have been isolated from different parts of dental tissue. Their participation in tissue repair and maintenance has been proposed [1]. Although it is difficult to characterize dental stem cells using surface protein markers, our results indicate the relative overexpression of important markers including CD13, CD34, CD73, and CD105 in DFs. These are ubiquitously expressed by all dental stem or precursor cells [6, 16]. With the exception of CD90, CD13, and CD34 which were frequently cited as dental-derived stem cell markers in 
previous studies, we selected CD106 (VCAM1) and CD166 (ALCAM), which are expressed more strongly in dental follicles. Other dental-derived stem marker genes including CD29, CD90, and CD73 were expressed at higher levels indicating self-renewing and differentiation capacities in DFs [33].

Interestingly, the gingiva expressed high levels of iPSassociated markers (OCT4, cMYC, SOX2, and KLK4) versus DFs [34]. These proteins are transcription factors that are essential for maintaining the self-renewal capacity or pluripotency [35]. The iPS cells offer an advantage over traditional MSCs because they display an unlimited growth capacity that can serve as an inexhaustible source of stem cells [36]. A similar comparable report analyzed that dental tissue derived mesenchymal-like stem cells can be reprogrammed into iPSCs more efficiently, when compared to other mature somatic cells from human body such as adult MSCs and adult dermal fibroblasts [37].

The accessibility of dental tissue, including MSCs, might still be limited because these cells can only be isolated under specific circumstances, such as during the extraction of teeth. However, the gingiva is one of the most convenient tissues to collect by biopsy, with less scar formation and less postsurgical donor discomfort. In addition, gingival tissues are routinely resected during dental procedures in children, such as surgical extraction of impacted teeth and surgical opening for teeth with delayed eruption, and these tissues are generally treated as biomedical waste. In the laboratory, it is also feasible to isolate stem cells from gingival tissue based on their highly proliferative nature. Thus, the gingiva can be an important alternative source of stem cells in regenerative dentistry. If stem cells isolated from gingival tissue can be utilized similar to the storage of umbilical cord blood, the dynamic features of these cells reveal much potential for their use. Although this study is limited to monitoring expression patterns without a clinical link, comparative gene expression analysis of different tissues might provide genetic information concerning functions, such as tissue repair and tooth development. Further investigations are needed to evaluate the neurogenesis capacity, mineralization potential, and cell proliferation capacity of stem cells from gingiva and dental follicles based on of this study.

\section{Conclusion}

For the first time, this study profiles differential gene expression between the gingiva and DFs. cDNA microarray was performed to characterize and compare the molecular fingerprints of stemness. The DFs have been considered a multipotent tissue based on their ability to generate cementum, bone, and PDL. While the gingiva was not noticed for pluripotent stemness before, this study demonstrated transcription factors of iPS cells were expressed at higher levels in the gingiva and most dental-derived stem cell markers were strongly upregulated in the DFs. Given the minimal postsurgical discomfort and simple accessibility of gingival tissue, the gingiva is a good candidate stem cell source in regenerative dentistry.

\section{Disclosure}

The funders had no role in study design, data collection and analysis, decision to publish, or preparation of the manuscript.

\section{Competing Interests}

The authors declare that there is no conflict of interests regarding the publication of this paper.

\section{Acknowledgments}

The authors gratefully acknowledge all participants for their collaboration. This research was supported by the Basic Science Research Program of the National Research Foundation of Korea (NRF) funded by the Ministry of Education, Science and Technology (2011-0022160 and 2012R1A1A2041910).

\section{References}

[1] T. I. Mitrano, M. S. Grob, F. Carrion et al., "Culture and characterization of mesenchymal stem cells from human gingival tissue," Journal of Periodontology, vol. 81, no. 6, pp. 917-925, 2010.

[2] P. M. Bartold, S. Shi, and S. Gronthos, "Stem cells and periodontal regeneration," Periodontology 2000, vol. 40, no. 1, pp. 164$172,2006$.

[3] S. Gronthos, M. Mankani, J. Brahim, P. G. Robey, and S. Shi, "Postnatal human dental pulp stem cells (DPSCs) in vitro and in vivo," Proceedings of the National Academy of Sciences of the United States of America, vol. 97, no. 25, pp. 13625-13630, 2000.

[4] M. Miura, S. Gronthos, M. Zhao et al., "SHED: stem cells from human exfoliated deciduous teeth," Proceedings of the National Academy of Sciences of the United States of America, vol. 100, no. 10, pp. 5807-5812, 2003.

[5] B. M. Seo, M. Miura, S. Gronthos et al., "Investigation of multipotent postnatal stem cells from human periodontal ligament," The Lancet, vol. 364, no. 9429, pp. 149-155, 2004.

[6] W. Sonoyama, Y. Liu, D. Fang et al., "Mesenchymal stem cellmediated functional tooth regeneration in Swine," PLoS ONE, vol. 1, no. 1, article e79, 2006.

[7] C. Morsczeck, W. Götz, J. Schierholz et al., "Isolation of precursor cells (PCs) from human dental follicle of wisdom teeth," Matrix Biology, vol. 24, no. 2, pp. 155-165, 2005.

[8] X. Xu, C. Chen, K. Akiyama et al., "Gingivae contain neuralcrest- and mesoderm-derived mesenchymal stem cells," Journal of Dental Research, vol. 92, no. 9, pp. 825-832, 2013.

[9] S. Yao, F. Pan, V. Prpic, and G. E. Wise, "Differentiation of stem cells in the dental follicle," Journal of Dental Research, vol. 87, no. 8, pp. 767-771, 2008.

[10] A. R. Ten Cate, "The development of the periodontium-a largely ectomesenchymally derived unit," Periodontology 2000, vol. 14, no. 1, pp. 9-19, 1997.

[11] C. Morsczeck, G. Schmalz, T. E. Reichert et al., "Gene expression profiles of dental follicle cells before and after osteogenic differentiation in vitro," Clinical Oral Investigations, vol. 13, no. 4, pp. 383-391, 2009.

[12] X. Han and S. Amar, "Identification of genes differentially expressed in cultured human periodontal ligament fibroblasts 
vs. human gingival fibroblasts by DNA microarray analysis," Journal of Dental Research, vol. 81, no. 6, pp. 399-405, 2002.

[13] T. Fujita, T. Iwata, H. Shiba et al., "Identification of marker genes distinguishing human periodontal ligament cells from human mesenchymal stem cells and human gingival fibroblasts," Journal of Periodontal Research, vol. 42, no. 3, pp. 283-286, 2007.

[14] H.-S. Lee, J. Lee, S.-O. Kim et al., "Comparative gene-expression analysis of the dental follicle and periodontal ligament in humans," PLoS ONE, vol. 8, no. 12, article e84201, 2013.

[15] J. S. Song, D. H. Hwang, S.-O. Kim et al., "Comparative gene expression analysis of the human periodontal ligament in deciduous and permanent teeth," PLOS ONE, vol. 8, no. 4, Article ID e61231, 2013.

[16] C. Morsczeck, G. Schmalz, T. E. Reichert, F. Völlner, K. Galler, and O. Driemel, "Somatic stem cells for regenerative dentistry," Clinical Oral Investigations, vol. 12, no. 2, pp. 113-118, 2008.

[17] K. Ranganathan and V. Lakshminarayanan, "Stem cells of the dental pulp," Indian Journal of Dental Research, vol. 23, no. 4, p. 558, 2012.

[18] M. Dominici, K. Le Blanc, I. Mueller et al., "Minimal criteria for defining multipotent mesenchymal stromal cells. The International Society for Cellular Therapy position statement," Cytotherapy, vol. 8, no. 4, pp. 315-317, 2006.

[19] R. P. Carmichael, C. A. McCulloch, and G. A. Zarb, "Quantitative immunohistochemical analysis of keratins and desmoplakins in human gingiva and peri-implant mucosa," Journal of Dental Research, vol. 70, no. 5, pp. 899-905, 1991.

[20] Š. Magister and J. Kos, “Cystatins in immune system," Journal of Cancer, vol. 4, no. 1, pp. 45-56, 2013.

[21] P. Ovaere, S. Lippens, P. Vandenabeele, and W. Declercq, "The emerging roles of serine protease cascades in the epidermis," Trends in Biochemical Sciences, vol. 34, no. 9, pp. 453-463, 2009.

[22] J. D. Rotty and P. A. Coulombe, "A wound-induced keratin inhibits Src activity during keratinocyte migration and tissue repair," Journal of Cell Biology, vol. 197, no. 3, pp. 381-389, 2012.

[23] A. E. Kalinin, A. V. Kajava, and P. M. Steinert, "Epithelial barrier function: assembly and structural features of the cornified cell envelope," BioEssays, vol. 24, no. 9, pp. 789-800, 2002.

[24] A. Antonelli, S. M. Ferrari, D. Giuggioli, E. Ferrannini, C. Ferri, and P. Fallahi, "Chemokine (C-X-C motif) ligand (CXCL)10 in autoimmune diseases," Autoimmunity Reviews, vol. 13, no. 3, pp. 272-280, 2014.

[25] Y. Hosokawa, I. Hosokawa, S. Shindo et al., "Black tea polyphenol inhibits CXCL10 production in oncostatin M-stimulated human gingival fibroblasts," International Immunopharmacology, vol. 11, no. 6, pp. 670-674, 2011.

[26] M. MacDougall, B. R. Dupont, D. Simmons et al., "Ameloblastin gene (AMBN) maps within the critical region for autosomal dominant amelogenesis imperfecta at chromosome 4q21," Genomics, vol. 41, no. 1, pp. 115-118, 1997.

[27] Y. D. Zhang, Z. Chen, Y. Q. Song, C. Liu, and Y. P. Chen, "Making a tooth: growth factors, transcription factors, and stem cells," Cell Research, vol. 15, no. 5, pp. 301-316, 2005.

[28] F. Liu, E. Y. Chu, B. Watt et al., "Wnt/ $\beta$-catenin signaling directs multiple stages of tooth morphogenesis," Developmental Biology, vol. 313, no. 1, pp. 210-224, 2008.

[29] T. Åberg, X.-P. Wang, J.-H. Kim et al., "Runx2 mediates FGF signaling from epithelium to mesenchyme during tooth morphogenesis," Developmental Biology, vol. 270, no. 1, pp. 7693, 2004.
[30] G. E. Wise, S. Frazier-Bowers, and R. N. D’Souza, "Cellular, molecular, and genetic determinants of tooth eruption," Critical Reviews in Oral Biology and Medicine, vol. 13, no. 4, pp. 323-334, 2002.

[31] I. Takahashi, M. Nishimura, K. Onodera et al., "Expression of MMP-8 and MMP-13 genes in the periodontal ligament during tooth movement in rats," Journal of Dental Research, vol. 82, no. 8, pp. 646-651, 2003.

[32] A. M. Havens, E. Chiu, M. Taba Jr. et al., "Stromal-derived factor-l $\alpha$ (CXCL 12) leveis increase in periodontal disease," Journal of Periodontology, vol. 79, no. 5, pp. 845-853, 2008.

[33] D. G. Phinney and D. J. Prockop, "Concise review: mesenchymal stem/multipotent stromal cells: the state of transdifferentiation and modes of tissue repair-current views," Stem Cells, vol. 25, no. 11, pp. 2896-2902, 2007.

[34] K. Takahashi and S. Yamanaka, "Induction of pluripotent stem cells from mouse embryonic and adult fibroblast cultures by defined factors," Cell, vol. 126, no. 4, pp. 663-676, 2006.

[35] N. Wada, B. Wang, N.-H. Lin, A. L. Laslett, S. Gronthos, and P. M. Bartold, "Induced pluripotent stem cell lines derived from human gingival fibroblasts and periodontal ligament fibroblasts," Journal of Periodontal Research, vol. 46, no. 4, pp. 438-447, 2011.

[36] K. Hynes, D. Menicanin, J. Han et al., "Mesenchymal stem cells from iPS cells facilitate periodontal regeneration," Journal of Dental Research, vol. 92, no. 9, pp. 833-839, 2013.

[37] X. Yan, H. Qin, C. Qu, R. S. Tuan, S. Shi, and G. T.-J. Huang, "iPS cells reprogrammed from human mesenchymal-like stem/progenitor cells of dental tissue origin," Stem Cells and Development, vol. 19, no. 4, pp. 469-480, 2010. 

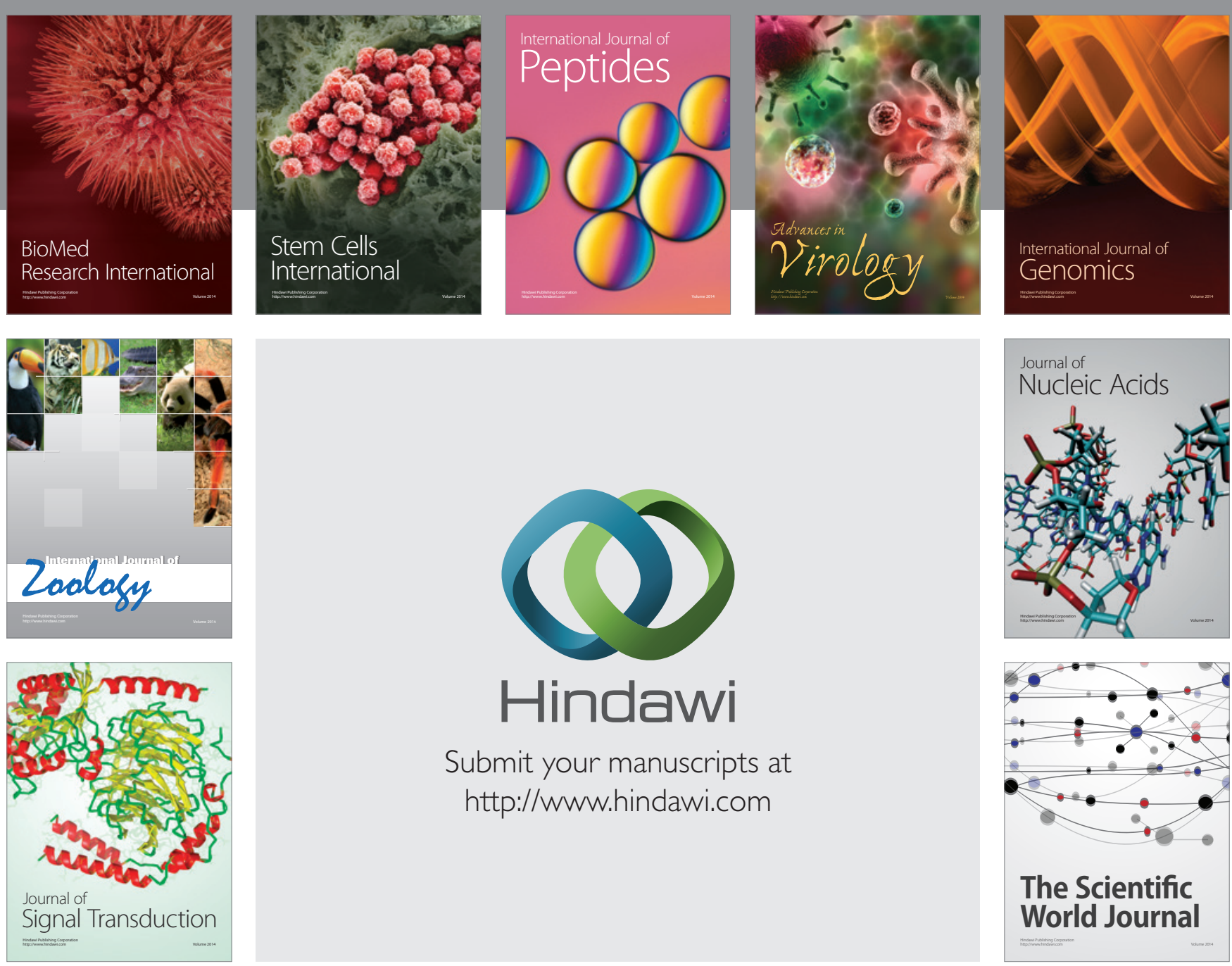

Submit your manuscripts at

http://www.hindawi.com
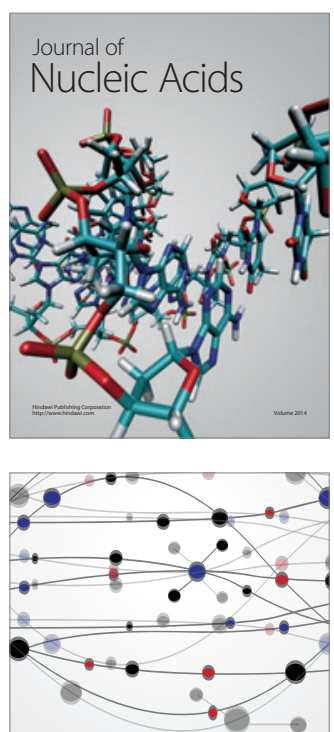

The Scientific World Journal
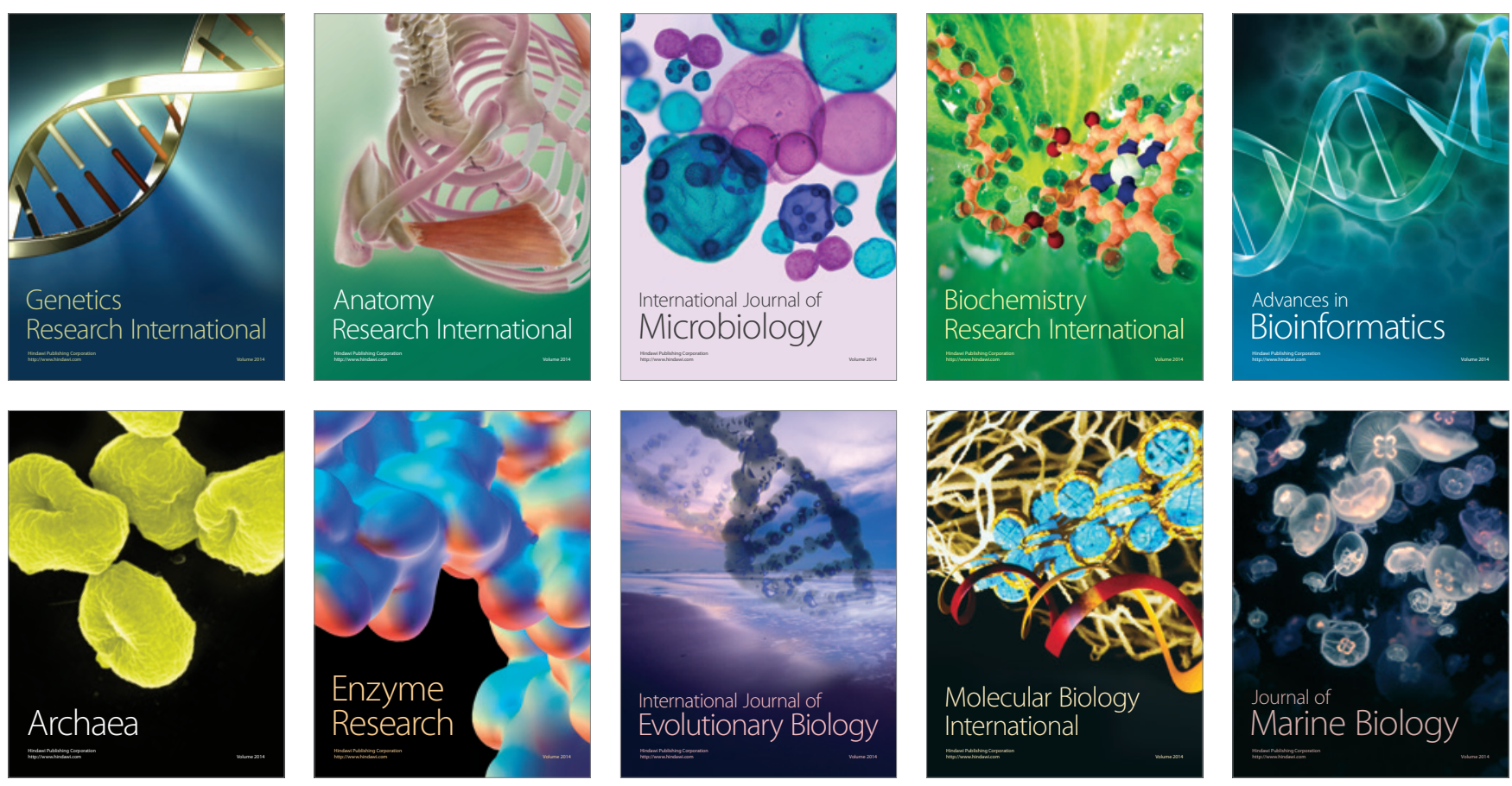